\title{
Highly Active Catalysts for the Telomerization of Crude Glycerol with 1,3-Butadiene
}

\author{
Regina Palkovits, ${ }^{[a]}$ Ilenia Nieddu, ${ }^{[b]}$ Robertus J. M. Klein Gebbink, ${ }^{[b]}$ and Bert M. Weckhuysen ${ }^{[a]}$
}

The first description of a telomerization reaction came from Smutny in 1967 who was studying the oligomerization and dimerization of 1,3-butadiene and its reactions with nucleophiles. ${ }^{[1]}$ Since then, numerous studies have appeared concentrated on monofunctional alcohols and other simple nucleophiles such as ammonia. ${ }^{[2-5]}$ So far, the only industrial application is the telomerization of butadiene with water leading to 2,7-octadien-1-ol. ${ }^{[6-8]}$ Surprisingly, not much work has been done on multifunctional nucleophiles, ${ }^{[9]}$ besides a few studies concerning the telomerization of sugar components or starch. ${ }^{[10]}$ We believe crude glycerol to be another interesting multifunctional nucleophile for this reaction. Governmental regulations in the European Union necessitate a growing usage of biodiesel and consequently a growing production along with an increasing supply of crude glycerol as the main by-product in the manufacture of biodiesel ( $226 \mathrm{~kg} / \mathrm{ton}$ ). Therefore, economically attractive technologies to directly convert crude glycerol into useful bulk chemicals or chemical building blocks are required. Various studies and recent reviews have focused, for instance, on synthesis gas from glycerol followed by Fischer-Tropsch synthesis. ${ }^{[11-16]}$ The telomerization of glycerol with 1,3-butadiene presents a promising technology allowing direct access to $\mathrm{C}_{8}$-chain mono-, di-, and triethers of glycerol with potential applications in surfactant chemistry and as chemical building blocks (Scheme 1).

Surprisingly, only one study concerning the telomerization of pure glycerol exists so $\mathrm{far}_{,}^{[17]}$ while the telomerization of crude glycerol has not been reported yet. Behr and Urschey described the telomerization of different polyglycols, including glycerol, using a Pd triphenylphosphine trisulfonic acid (tppts) catalyst. ${ }^{[17]}$ For pure glycerol, turnover numbers (TONs) up to 990 with a turnover frequency (TOF) of $248 \mathrm{~h}^{-1}$ were reached, resulting mainly in formation of the monoether and summing up to a total TON of 3300 as the catalyst system was recycled five times. Inspired by the broad applicability of this reaction type and the little number of studies on glycerol telomerization, we looked deeper in this topic and investigated the electronic and structural requirements of potentially active catalyst systems. Herein, we report a system of Pd in combination with methoxy-functionalized $\mathrm{PPh}_{3}$ as a highly active catalyst for the

[a] Dr. R. Palkovits, Prof. Dr. B. M. Weckhuysen

Inorganic Chemistry and Catalysis Group

Department of Chemistry, Utrecht University

Sorbonnelaan 16, 3584CA Utrecht (The Netherlands)

Fax: (+31) 30-251-1027

E-mail:b.m.weckhuysen@uu.nl

[b] Dr. I. Nieddu, Prof. Dr. R. J. M. Klein Gebbink

Chemical Biology \& Organic Chemistry

Department of Chemistry, Utrecht University

Padualaan 8, 3584CH Utrecht (The Netherlands)

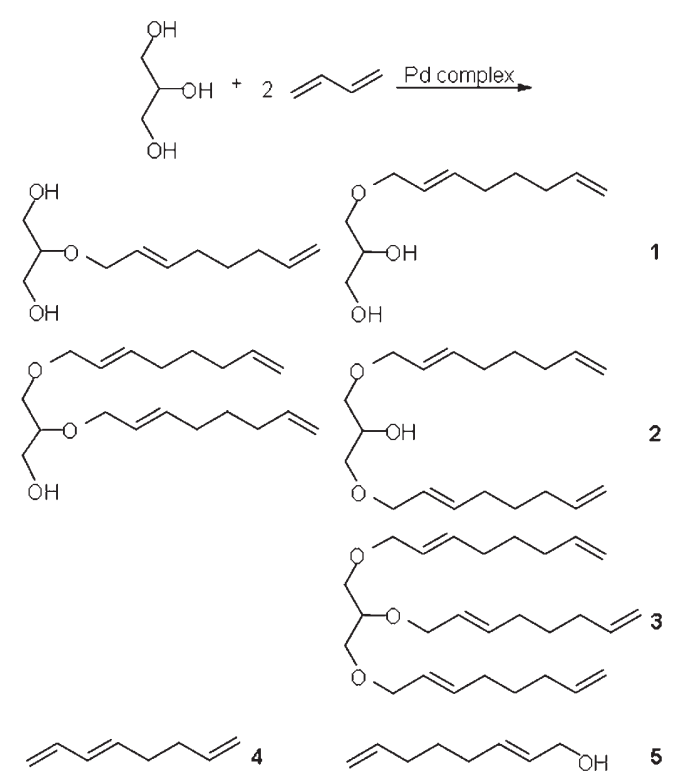

Scheme 1. Telomerization of glycerol with butadiene to form glycerol ethers 1-3 and by-products octatriene 4 and octadienol 5 .

telomerization of both pure and crude glycerol reaching TONs of up to 8545 in one run and a TOF of $3418 \mathrm{~h}^{-1}$. An overview of the investigated ligand systems that focus on methoxy-functionalized triphenylphosphine species is given in Scheme 2. Methoxy substituents exhibit electron-donating properties, thus enhancing the electron density on the phosphorous
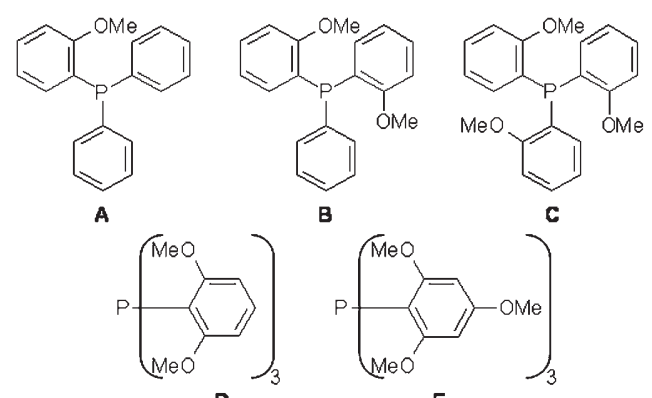

B
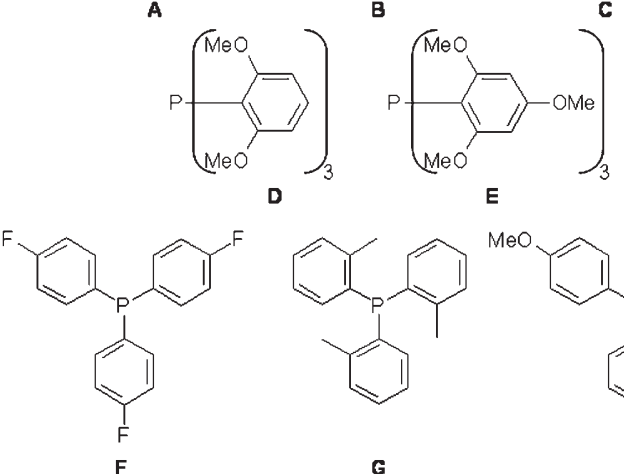

E

Scheme 2. Structures of the ligands investigated for the telomerization of glycerol. 
Table 1. The activity of different catalysts in the telomerization of pure and crude glycerol with 1,3-butadiene. ${ }^{[a]}$

\begin{tabular}{|c|c|c|c|c|c|c|c|c|}
\hline \multirow[t]{2}{*}{ Entry } & \multirow[t]{2}{*}{ Ligand } & \multirow[t]{2}{*}{$t[\mathrm{~h}]$} & \multirow[t]{2}{*}{ Yield [\% $]^{[b]}$} & \multicolumn{3}{|c|}{ Selectivity [\%] $]^{[c]}$} & \multirow[t]{2}{*}{$\mathrm{TON}^{[\mathrm{d}]}$} & \multirow[t]{2}{*}{ TOF $\left[h^{-1}\right]$} \\
\hline & & & & 1 & 2 & 3 & & \\
\hline \multicolumn{9}{|c|}{ pure glycerol } \\
\hline 1 & A & 5 & 33.3 & 42 & 30 & 28 & 1001 & 200 \\
\hline 2 & B & 1 & 67.5 & 46 & 31 & 23 & 1802 & 1802 \\
\hline 3 & $\mathrm{C}$ & 0.5 & 67.1 & 58 & 29 & 14 & 1520 & 3040 \\
\hline 4 & $C^{[e]}$ & 2.5 & 66.3 & 43 & 38 & 19 & 8545 & 3418 \\
\hline 5 & D & 5 & 72.8 & 36 & 35 & 28 & 2245 & 449 \\
\hline 6 & $E$ & 5 & 11.7 & 69 & 28 & 2 & 252 & 50 \\
\hline 7 & $\mathbf{F}$ & 5 & 0.5 & n.d. & n.d. & n.d. & 14 & 3 \\
\hline 8 & G & 5 & 2.1 & n.d. & n.d. & n.d. & 51 & 10 \\
\hline 9 & $\mathbf{H}$ & 5 & 0.8 & n.d. & n.d. & n.d. & 18 & 4 \\
\hline \multicolumn{9}{|c|}{ crude glycerol } \\
\hline 10 & $\mathrm{C}$ & 0.75 & 56.0 & 20 & 24 & 56 & 1773 & 2335 \\
\hline 11 & C & 1.5 & 71.0 & 32 & 31 & 37 & 2159 & 1435 \\
\hline 12 & C & 0.5 & 24.1 & 36 & 51 & 12 & 696 & 1392 \\
\hline
\end{tabular}

[a] Butadiene/glycerol $=2.5$, catalyst concentration: $0.06 \mathrm{~mol} \%\left[\mathrm{Pd}(\mathrm{acac})_{2}\right]$ with respect to glycerol, $\mathrm{P} / \mathrm{Pd}=5, T=80^{\circ} \mathrm{C}$, n.d. $=$ not determined. $[\mathrm{b}] \mathrm{Based}$ on conversion of glycerol into glycerol ethers. [c] Based on yields of glycerol ethers. [d] Based on glycerol conversion: one catalytic cycle is defined as TON=

1 , therefore triether formation requires TON $=3$. [e] Amount of catalyst decreased to $20 \%$.

atom. Consequently, the electron density at the phosphorous atom increases with the number of methoxy substituents. At the same time, steric constraints increase and coordination of substrates towards the corresponding palladium complex may be hindered. Table 1 summarizes the changes in activity depending on the ring substitution (entries 1-6). Different reaction times result as all reactions were stopped after completion indicated by a pressure drop to around 1 bar. If no pressure drop could be observed as a result of low catalyst activity, the reactions were stopped after $5 \mathrm{~h}$ reaction time. By varying the ligand substitution from one methoxy group on a single phenyl ring $(A)$ to three methoxy groups on each ring $(E)$, the TON increases reaching a maximum of 2245 for $\mathbf{D}$ (Table 1, entry 5), a triphenylphosphine ligand with methoxy groups in both ortho positions of each ring. On the other hand, a rather long reaction time of $5 \mathrm{~h}$ is required. Therefore, the overall maximum in activity can be found for tris(ortho-methoxyphenyl)phosphine (tompp, C; Table 1, entry 3 ) reaching a comparable yield in only 0.5 instead of $5 \mathrm{~h}$ and resulting in a significantly higher TOF of $3040 \mathrm{~h}^{-1}$ compared to $449 \mathrm{~h}^{-1}$ for D. To elucidate the real performance of tompp in this reaction, we decreased the amount of Pd/tompp to just $20 \%$ of the original amount (Table 1, entry 4). Consequently, the required reaction time to reach a comparable yield increased five times to $2.5 \mathrm{~h}$ and a TOF of $3418 \mathrm{~h}^{-1}$ and a TON of 8545 were observed. Thus, compared to the Pd/tppts system, ${ }^{[17]}$ TONs in one run could be increased substantially together with a significantly shortened reaction time.

The high activity of the methoxy-functionalized $\mathrm{Pd} / \mathrm{PPh}_{3}$ catalyst systems points towards a positive effect of electron-donating groups. This result is particularly interesting as several studies concerning the ideal electronic structure of potential phosphine ligands for telomerization reactions came to the conclusion that $\pi$-acceptor rather than $\sigma$-donor properties are advantageous for catalytic activity and regioselectivity. ${ }^{[4,18]}$ As the electron density on the phosphorous atom increases with the number of methoxy groups on the phenyl rings, the observed maximum in activity for $\mathbf{C}$ indicates an optimum electron density for one methoxy group on every ring. Additionally, steric hindrance increases with the number of substituents on the ring systems and probably results in hindered substrate coordination and a consequently lower activity of the catalyst with higher substituted $\mathrm{PPh}_{3}$ ligands (D and E). Tompp (C) seems therein to combine increased electron density on the phosphorous with steric constraints leading to high catalytic activity. To emphasize the advantageous effect of electron-donating substituents, a $\mathrm{PPh}_{3}$ ligand with fluorine as electronwithdrawing group $\mathbf{F}$ was tested (Table 1, entry 7) but did not show any activity. Therefore, increased electron density on the phosphorous atom seems to be advantageous to achieve improved catalytic activity.

Interestingly, $\mathrm{Pd} /$ tompp as catalyst system has, to the best of our knowledge, not been reported yet for telomerization reactions. Some studies, however, mention tris(ortho-tolyl)phosphine (G) and tris(para-methoxyphenyl)phosphine $(\mathbf{H})$, both of which show medium catalytic activity in the telomerization of butadiene with arabinose und xylose. ${ }^{[19]}$ In that study, $\mathbf{G}$ and $\mathbf{H}$ show comparable activity to phosphines exhibiting $\pi$-acceptor properties such as fluorine- $(\mathbf{F})$ or chlorine-functionalized $\mathrm{PPh}_{3}$ ligands. Therefore, we investigated $\mathbf{G}$ and $\mathbf{H}$ in the telomerization of glycerol also expecting a reasonable catalytic activity, as electron-donating substituents were identified to be advantageous for the catalytic activity in this reaction. Enhanced electron density on the phosphorous was emphasized by ${ }^{31} \mathrm{P}$ NMR spectroscopy, which revealed the phosphorous resonance for C at $\delta=-38.0 \mathrm{ppm}$ and at $\delta=-27.9 \mathrm{ppm}$ in the case of ligand G. Surprisingly, however, neither $\mathrm{PPh}_{3}$ with electron-donating methyl groups in the ortho position (G; Table 1, entry 8) nor with methoxy groups in the para position $(\mathbf{H}$; entry 9$)$ resulted in a reasonable activity, showing instead TONs below 50 after $5 \mathrm{~h}$ reaction time. On the basis of these results, we came to the conclusion that other factors beside the electron density 
at the phosphorous atom play a crucial role for the catalytic activity of $\mathrm{Pd} / \mathrm{PPh}_{3}$-type catalysts in the telomerization of 1,3butadiene with glycerol and probably other multifunctional nucleophiles as well. Herein, one point may be the polarity of methoxy groups as compared to methyl groups which leads to an improved solubility of methoxy-functionalized ligands and the corresponding complexes in a polar substrate such as glycerol. Consequently, the low polarity of methyl-functionalized $\mathrm{PPh}_{3}$ (G) hinders dissolution of the ligand and results in a rather low activity. On the other hand, $\mathbf{H}$ should exhibit comparable properties in terms of electron density on the phosphorous and polarity as for tompp (C). Nevertheless, no significant activity was observed with $\mathbf{H}$ as ligand (Table 1, entry 9) indicating that the ortho position of the methoxy species may additionally play an important role. Presumably, explanations for this could be the stabilization of the Pd complex by methoxy groups in the ortho position caused by the formation of a hemilabile species and the difference in the resulting cone angle dependent on a substituent in the ortho or para position, respectively. ${ }^{[19,20]}$ Further investigations will be performed to elucidate the exact role of methoxy subsituents in ortho and para positions.

Another important point besides the high activity of the catalyst system is its product selectivity. Possible by-products of the telomerization reaction are the butadiene dimer octatriene 4 and octadienol 5, which result from the telomerization of butadiene with water. The amount of by-products, however, was below $5 \%$ for all reactions and thus not investigated. In terms of product distribution, we performed a variation of the butadiene/glycerol ratio (1-4) at constant reaction time and temperature (Table 2). On increasing the butadiene/glycerol ratio from 1 to 4 (Table 2, entries 1-4), the yield of glycerol ethers increases to $92 \%$ with a TON of 2626 . At the same time, the amount of monoether decreases from 70 to around $40 \%$ while the amount of diether increases. Therefore, higher amounts of butadiene seem to accelerate the telomerization reaction but result at the same time in a shift towards enhanced di- and triether formation. Clearly, to promote formation of the monoether, a rather low butadiene/glycerol ratio should be chosen.

The focus for our study, however, was the feasibility of a direct telomerization of crude glycerol resulting from the pro- duction of biodiesel. Crude glycerol contains, besides traces of ash and various metals and ions, around $10 \%$ water. In this regard, we studied tompp as ligand system not only for pure glycerol but also for crude glycerol as substrate. The results are promising (Table 1, entries 10-12 and Table 2, entry 5), revealing clearly the feasibility of the telomerization of crude glycerol. For a butadiene/glycerol ratio of 2.5 , yields of up to $71 \%$ with a TON of 2159 were obtained, and even higher yields and TONs are feasible by choosing a butadiene/glycerol ratio of 4 . The activity of the catalyst for crude glycerol is comparable with that for pure glycerol as substrate and is reached within slightly prolonged reaction times. Owing to the increased water content of the substrate, up to $15 \%$ octadienol was observed as by-product. In terms of product distribution, the formation of the triether increases which may be a minor drawback given that mono- and diethers are target molecules for surfactant applications. ${ }^{[17]}$ Nonetheless, these differences in product distribution may be induced by the somewhat prolonged reaction time until a complete uptake of butadiene is reached. Therefore, an additional experiment was performed that could support this theory. Therein, the telomerization of crude glycerol was stopped after 30 min resulting as expected in a lower yield as compared to pure glycerol of around $24 \%$. The observed product distribution, however, was similar to pure glycerol with little increased diether formation for crude glycerol compared to pure glycerol under similar reaction conditions (Table 1, entry 3 vs 12). These results emphasize that the product distribution is basically dependent on the butadiene/glycerol ratio and the reaction time rather than on pure or crude glycerol as substrate.

In summary, we have demonstrated the successful telomerization of glycerol with 1,3-butadiene by applying a Pd/tompp complex. The catalyst system shows superior activity relative to the known Pd/tppts system and maintains its high activity even for crude glycerol as substrate. Future investigations will focus on a variation of different reaction parameters and on a mechanistic understanding to improve the activity and selectivity of the telomerization reaction towards chosen target molecules.

\begin{tabular}{|c|c|c|c|c|c|c|c|c|}
\hline \multirow[t]{2}{*}{ Entry } & \multirow{2}{*}{$\begin{array}{l}\text { Butadiene/ } \\
\text { glycerol }\end{array}$} & \multirow[t]{2}{*}{$t[\mathrm{~h}]$} & \multirow[t]{2}{*}{ Yield [\%] ${ }^{[b]}$} & \multicolumn{3}{|c|}{ Selectivity [\%] ${ }^{[c]}$} & \multirow[t]{2}{*}{ TON $^{[d]}$} & \multirow[t]{2}{*}{$\operatorname{TOF}\left[h^{-1}\right]$} \\
\hline & & & & 1 & 2 & 3 & & \\
\hline \multicolumn{9}{|c|}{ pure glycerol } \\
\hline 1 & 1 & 0.5 & 47.7 & 70 & 32 & 15 & 737 & 1474 \\
\hline 2 & 2 & 0.5 & 62.4 & 60 & 29 & 10 & 1390 & 2780 \\
\hline 3 & 2.5 & 0.5 & 67.1 & 58 & 29 & 14 & 1520 & 3040 \\
\hline $\begin{array}{l}4 \\
\text { crude }\end{array}$ & 4 & 0.5 & 92.3 & 39 & 44 & 16 & 2626 & 5182 \\
\hline 5 & 4 & 1.5 & 72.5 & 20 & 24 & 56 & 2312 & 1581 \\
\hline
\end{tabular}

[a] Catalyst concentration: $0.06 \mathrm{~mol} \%\left[\mathrm{Pd}(\mathrm{acac})_{2}\right]$ with respect to glycerol, $\mathrm{P} / \mathrm{Pd}=5, T=80^{\circ} \mathrm{C}$. [b] Based on conversion of glycerol into glycerol ethers. [c] Based on yield of glycerol ethers. [d] Based on glycerol conversion: one catalytic cycles is defined as $\mathrm{TON}=1$, therefore triether formation requires $\mathrm{TON}=3$.

\section{Experimental Section}

In a typical telomerization experiment, $\left[\mathrm{Pd}(\mathrm{acac})_{2}\right] \quad(22.8 \mathrm{mg}, 7.5 \times$ $10^{-5} \mathrm{~mol} ; \quad$ acac $=$ acetylacetonate) and the triphenylphosphine-type ligand $\left(3.75 \times 10^{-4} \mathrm{~mol}\right) \quad$ were added to glycerol $(11.51 \mathrm{~g}$, $0.125 \mathrm{~mol})$. The solution was directly mixed inside a $50-\mathrm{mL}$ stainless steel Parr autoclave and flushed three times with argon. The autoclave was cooled down to $258 \mathrm{~K}$ using an acetone-dry ice mixture. 1,3-butadiene was directly condensed in the reactor, and the autoclave was heated to the reaction 
temperature of $353 \mathrm{~K}$ and kept at that temperature for $5 \mathrm{~h}$ or until the pressure had dropped to 1 bar. After the reaction, the reactor system was cooled to room temperature and flushed several times with argon. The reactor content was analyzed using a gas chromatography system (Shimadzu GC-2010) with a SupelcoWax10 column (internal calibration). As none of the reaction products are commercially available, product identification and GC calibration were attained by column separation of several reaction mixtures. Several separated fractions were investigated by GC, GC-MS, and ${ }^{1} \mathrm{H}$ NMR spectroscopy measurements, allowing us to assign the different mono-, di-, and triethers of glycerol and to use the identified clean fractions of the main components for the GC calibration. Branched products were not observed in any ${ }^{1} \mathrm{H}$ NMR spectra but cannot be fully excluded. ${ }^{31} \mathrm{P}$ NMR measurements were carried out using $\mathrm{CDCl}_{3}$ as solvent. Butadiene and argon were purchased from Linde Gas Benelux, and chemicals were obtained from Aldrich and used without any purification.

\section{Acknowledgements}

ACTS-ASPECT is acknowledged for financial support.

Keywords: glycerol • palladium • phosphane ligands telomerization

[1] E. J. Smutny, J. Am. Chem. Soc. 1967, 89, 6793-6794.

[2] F. Vollmüller, J. Krause, S. Klein, W. Mägerlein, M. Beller, Eur. J. Inorg. Chem. 2000, 1825-1832.

[3] F. Vollmüller, W. Mägerlein, S. Klein, J. Krause, M. Beller, Adv. Synth. Catal. 2001, 343, 29-33.
[4] R. Jackstell, M. G. Andreu, A. Frisch, K. Selvakumar, A. Zapf, H. Klein, A. Spannenberg, D. Röttger, O. Briel, R. Karch, M. Beller, Angew. Chem. 2002, 114, 1028-1031; Angew. Chem. Int. Ed. 2002, 41, 986-989.

[5] T. Prinz, W. Keim, B. Drießen-Hölscher, Angew. Chem. 1996, 108, 18351836; Angew. Chem. Int. Ed. Engl. 1996, 35, 1708-1710.

[6] N. Yoshimura in Aqueous-Phase Organometallic Catalysis (Eds.: B. Cornils, W. A. Herrmann), Wiley-VCH, Weinheim, 1998, pp. 408-410.

[7] D. Röttger; A. Tuchlenski, German Patent, 2002, DE 10105751 A1.

[8] D. Röttger, M. Beller, R. Jackstell, H. Klein, K.-D. Wiese, DE 10128144 A1, 2002.

[9] K. Hill, S. Axt, K. J. Weese, WO 9302032, 1993.

[10] V. Desvergnes, C. Pinel, P. Gallezot, Green Chem. 2001, 3, 175-177.

[11] J. N. Cheda, J. A. Dumesic, Catal. Today 2007, 123, 59-70.

[12] S.-H. Chai, H.-P. Wang, Y. Liang, B.-Q. Xu, J. Catal. 2007, 250, 342-349.

[13] R. R. Soares, D. A. Simonetti, J. A. Dumesic, Angew. Chem. 2006, 118, 4086-4089; Angew. Chem. Int. Ed. 2006, 45, 3982-3985.

[14] A. Corma, S. Iborra, A. Velty, Chem. Rev. 2007, 107, 2411-2502.

[15] G. W. Huber, A. Corma, Angew. Chem. 2007, 119, 7320-7338; Angew. Chem. Int. Ed. 2007, 46, 7184-7201.

[16] M. Pagliaro, R. Ciriminna, H. Kimura, M. Rossi, C. Della Pina, Angew. Chem. 2007, 119, 4516-4522; Angew. Chem. Int. Ed. 2007, 46, 44344440 .

[17] A. Behr, M. Urschey, Adv. Synth. Catal. 2003, 345, 1242-1246.

[18] T. Prinz, B. Driessen-Hölscher, Chem. Eur. J. 1999, 5, 2069-2076.

[19] B. Estrine, S. Bouquillon, F. Hénin, J. Muzart, Eur. J. Org. Chem. 2004, 2914-2922.

[20] S. Borns, R. Kadyrov, D. Heller, W. Baumann, A. Spannenberg, R. Kempe, J. Holz, A. Börner, Eur. J. Inorg. Chem. 1998, 1291-1295.

Received: November 11, 2007

Revised: November 26, 2007

Published online on January 21, 2008 